\title{
HOST AND OVIPOSITIONAL PREFERENCE OF RICE WEEVIL (SITOPHILUS ORYZAE) DEPENDING ON FEEDING EXPERIENCE
}

\author{
GVOZDENAC, S. ${ }^{1}$ - TANASKOVIĆ, S. ${ }^{2}$ - VuKAJlOVIĆ, F. ${ }^{3}$ - PrVULOVIĆ, D. ${ }^{4}$ - OVUKA, J. ${ }^{1}-$ \\ VIŠACKI, V. ${ }^{4}-$ SEDLAR, A. ${ }^{4 *}$ \\ ${ }^{1}$ Institute of Field and Vegetable Crops, Novi Sad, Serbia \\ (phone: +381-21-489-8326; fax: +381-21-641-3833) \\ ${ }^{2}$ Faculty of Agronomy, University of Kragujevac, Čačak, Serbia \\ (phone: +381-32-303-410; fax: +381-32-303-401) \\ ${ }^{3}$ Faculty of Science, University of Kragujevac, Čačak, Serbia \\ (phone: +381-34-336-223; fax: +381-34-335-040) \\ ${ }^{4}$ Faculty of Agriculture, University of Novi Sad, Novi Sad, Serbia \\ (phone: +381-21-459-3373; fax: +381-21-459-761) \\ *Corresponding author \\ e-mail:alek@polj.uns.ac.rs; phone: + 381-63-507-571; fax: + 381-21-459-989
}

(Received 27 $7^{\text {th }}$ Apr 2020; accepted $13^{\text {th }}$ Aug 2020)

\begin{abstract}
Rice weevil, Sitophilus oryzae is one of the most devastating primary pests of stored grains. Adults feed mainly on endosperm, while larvae feed on germ, resulting in reduced germination and nutritional value of kernels. The influence of a commodity condition on the food preferences of S. oryzae has been well documented, but the influence of previous feeding experience ("natal habitat preference induction" - NHPI theory) has not yet been confirmed. This research aims to test the NHPI theory, to study the behavioural responses of $S$. oryzae virgin males and females to different grains (maize, wheat and barley) depending on rearing substrate and feeding history and to test host, feeding and oviposition preference. In a "Choice test", the host preference was determined based on the adult distribution on specific grains, feeding preferences based on grain damage (\%) and grain loss (\%), and ovipositional preference based on the progeny production. The results indicate that host, feeding and ovipositional preference of $S$. oryzae was not dependent on the previous feeding experience. Maize was the most preferential grain, regardless on the rearing substrate, for both male and female weevils. Grain damage, weight loss and progeny production were higher on maize, regardless on the rearing history.
\end{abstract}

Keywords: maize, grains, storage pest, food attractiveness, progeny

\section{Introduction}

In general, annual grain losses in storages due to the presence of insect pests approach 15\% (Joshi et al., 1991), while the maximum grain loss attributed to a single weevil species reached $19 \%$ in wheat and nearly $57 \%$ in rice (Banerjee and Nazimuddin, 1985).

Rice weevil, Sitophilus oryzae (Linnaeus, 1763), (Coleoptera: Curculionidae) is one of the most economically damaging primary pests of stored grains, primarily barley, maize, rice, and wheat (Atwal and Dhaliwal, 2002). This pest causes the highest damage to grains that are stored at $25-30{ }^{\circ} \mathrm{C}$ and at low relative humidity (Batta, 2004). Adult weevils feed mainly on endosperm, reducing the carbohydrate content while larvae feed preferentially on germ, resulting in reduced germination and nutritional value due to removal of a large percentage of the proteins and vitamins. Nonetheless, the kernel 
damage caused by $S$. oryzae enables other species, secondary pests (external feeders) to additionally damage the grain. Similarly, Zakladnoi and Ratanova (1987) reported that during the development, larvae consume about $50 \%$ of the total grain weight. Additionally, seed germination is reduced and infested grain is more susceptible to infestation by other associated pests and pathogens. Although polyphagous pests consume and develop on a wide range of hosts, their behaviour is influenced by several physical and chemical factors. The influence of a commodity condition on the food preferences of $S$. oryzae has been well documented, but available data on the influence of previous feeding experience (at a larval stage) on food preference are scarce (Trematerra et al., 2013). Some authors report that a previous experience on host plants can modify insects feeding behavior. Since the induction of insect's preference to host plants varies depending on both, plant and insect species, it is necessary to investigate each insect-host plant interaction to determine if this phenomenon occurs or not (Boica Junior et al., 2016).

The most comprehensive review on the storage insect-host plant interactions was published by Trematerra et al. (2013) who summarized theories on insect host preference. As mentioned by Trematerra et al. (2013), theories like Hopkins host selection principle (Dethier, 1954), neo-Hopkins principle (Jaenike, 1983) and "chemical legacy hypothesis" (Corbet, 1985) tend to explain how can host preferences be induced without being genetically fixed. The Hopkins host selection principle (Hopkins, 1917) assumes that a memory of the feeding substrate is formed during the larval stage, stored in the central nervous system and transferred across metamorphosis to the adult stage. This phenomenon is called "preimaginal conditioning" (Thorpe and Jones, 1937; van Hemden et al., 1996; Barron, 2001; Blackiston et al., 2008). The "neoHopkins principle" (Jaenike, 1983) postulates that the host preference is determined at the adult stage shortly after the emergence from pupa ("early adult experience") (Van Emden et al., 1996). To date, the most comprehensive theory on the induction of host plant preferences is the "chemical legacy hypothesis" (Corbet, 1985). Based on this theory, small amounts of molecules of environmental chemicals inside the insect body or on the body surface at larval or pupal stage are assumed to influence the adult's food preferences. In this case, induction might happen in any developmental stage by contact with traces of chemicals transferred from an earlier stage. In this theory, no "learning" and no "memory" transfer among stages is required.

Mentioned theories, that were based on the results from several studies, support the idea that the experience with plant chemical residuals at the larval and/or adult stage can influence adult preference. However, in most studies, it has been difficult to identify the specific factors by which larval experience has changed adult behaviour because several learning mechanisms are involved. As Dethier noted in 1982, the mechanisms by which natal experiences affect later preferences vary. Therefore, he endorsed the more general term to describe situations in which experience with particular stimuli (plant chemical) increases preferences for the same stimuli "preference induction" or "natal habitat preference induction" - NHPI (Davis and Stamps, 2004). Namely, NHPI is an umbrella concept that encompasses a few more specialized terms, such as the Hopkins host selection principle and the "chemical legacy".

According to the NHPI hypothesis, phytophagous insect females prefer to lay their eggs on the host species on which they developed as larvae (Schoonhoven et al., 1998). As mentioned by Davies (2004), at this point, NHPI in the strict sense has been observed in relatively few species, so additional studies of this phenomenon are 
necessary. Even though there are numerous studies on the factors that affect the behaviour of $S$. oryzae in relation to previous experience at the adult stage, there is still inadequate information about the effect of natal exposure to specific nutrient medium. Food selection under natural conditions is influenced by various chemical and physical factors that affect insects' behaviour, ecological interactions and developmental or physiological status. Effects of feeding experience on food preference have been shown in various phytophagous insects, including stored-grain pests, as reported by Davis and Stamps (2004).

The relationship between preference of ovipositing females to certain plant species, growth, survival, and reproduction of offspring on those plants has been a central problem in the theory of insect-plant interactions. For Sitophilus zeamais (Motschulsky, 1855), it has been confirmed that females tend to lay eggs on maize kernels that are subjected to multiple visits, which emphasizes the significance of "already visited" kernels (Danho and Haubruge, 2003). However, for stored-product weevils, it is not clear what is the benefit from the oviposition on already-visited and infested kernels. Generally, it is considered that stored-product weevils differ significantly in foodmediated oviposition selection. As reported by Danho and Haubruge (2003), seed beetles like $S$. zeamais, can lay multiple eggs in a seed, increasing the competition among the larvae, while females of other species like bruchids, usually avoid competition during oviposition. As reported by Russell (1968), "kernel size" is a factor that also influences ovipositional preference of grain weevils and should not be overlooked.

As mentioned earlier, the influence of a specific commodity condition on $S$. oryzae development and preference depending on food quality has been well documented, but there are only a few available information for the nutritional preferences in relation to previous experience of food at larval stage. According to the NHPI hypothesis, phytophagous insect females prefer to lay eggs on the plant species on which they developed as larvae. This research aims to study the behavioral responses of virgin $S$. oryzae male and female adults to different grains on which they were not reared, and to test the NHPI hypothesis. Additionally, this work aimed to gain the information on host, feeding and oviposition preference of S. oryzae.

\section{Material and methods}

This work aimed to assess the feeding preference of $S$. oryzae weevils to different grains, in relation to previous feeding experience, as well as to test the NHPI hypothesis on this species. The influence of one factor- feeding experience at larval stage (i.e. rearing substrate) on host, feeding and oviposition preference of adults was assessed based on following indices: male and female distribution on different offered grains in a "Choice test", grain damage $(\%)$, remained grain weight $(\mathrm{g})$, weight loss (g) and progeny production (male and female weevils).

\section{Insect culture}

S. oryzae weevils were reared for 10 generations on wheat kernels, variety Pobeda (wheat-reared weevils) and dent type maize kernels, hybrid NS640, (maize-reared weevils), in controlled conditions, at $27 \pm 1{ }^{\circ} \mathrm{C}, 70 \pm 5 \% \mathrm{RH}$ and in continuous darkness (Trematerra et al., 2013). 
Newly emerged, less than 12-h-old adults of S. oryzae, were collected from rearing jars containing wheat and maize. The weevils were sexed for the assay, individually according to the shape of the rostrum, which is distinctly longer, narrower and smoother in the females than in males (Halstead 1963) and pronotum characters (Nardon and Nardon, 2002). Weevils were starved $24 \mathrm{~h}$ before setting up the experiment.

\section{Host and feeding preference}

In a "Choice test", host and feeding preference parameters were determined.

The host preference was assessed based on the mean number of weevils in each Petry dish (males, females and males + females), attracted to different grains, after each exposure period. To determine the response of $S$. oryzae males and females to different grains, 20 sexed weevils were placed from the rearing substrate in the center of test arena, a plastic container with a lid $(60 \times 40 \times 25 \mathrm{~cm})$. Four treatments containing $100 \mathrm{~g}$ of wheat, maize and barley were offered in separate Petri dishes $(\varnothing 9 \mathrm{~cm})$. Three Petri dishes were placed in the test arena and the assay was carried out for 50 days, but the readings were made after 12, 36 and $60 \mathrm{~h}$, and 7, 25 and 50 days.

Feeding preference parameters included: grain damage, remained grain weight and weight loss (expressed in \%). Damaged grains were separated manually from undamaged grains using a magnifying glass and were weighed, separately. Percent of grain damage was calculated using the following formula:

$$
\text { Grain damage }(\%)=\frac{\text { number of damaged grains }}{\text { total number of grains }} \times 100
$$

Upon the conclusion of the experiment (50 days) and after the new generation emergence, weight loss was calculated based on the weight at the beginning of the experiment and weight of grains after the exposure of 50 days and the removal of insects. Experiment was replicated six times.

\section{Ovipositional preference and progeny production}

Ovipositional preference was assessed based on the progeny production. From each substrate, and replicate, after the termination of the feeding preference assay ( 25 days), the adults were removed and Petri dishes with grains were closed and maintained at the same temperature for an additional period, up to 50 days from the beginning of the experiment. After 50 days, dishes were opened, and live adult progeny was counted.

All experiments were performed at $27 \pm 1{ }^{\circ} \mathrm{C}, 70 \pm 5 \% \mathrm{RH}$, in continuous darkness, as the rearing of parenteral population. Experiments were set in six replications.

\section{Statistical analysis}

The differences between distribution percent of weevils on different grains, the amount of consumed food and difference in progeny production were tested using Bonferroni test and Students T test in statistical Software SPSS 17, for the confidence interval of $95 \%$. To determine the strength of the differences between groups the effect size was calculated using Eta squared test (Cohen, 1992). 


\section{Results}

\section{Host and feeding preference}

The number of weevils in different commodities significantly differed among recording periods. When provided with a choice of grains, wheat-reared males and females showed higher preference to maize and barley, compared to the wheat. In the first reading (after $12 \mathrm{~h}$ ), the distribution of wheat-reared S. oryzae females in Petri dishes was $73 \%$ on maize, $22 \%$ on barley and $5 \%$ on wheat. This trend remained throughout the experiment. In the same period, males from wheat-reared population were distributed as follows: $67 \%$ of individuals on maize, $32 \%$ on barley and 1\% on wheat (Fig. 1). The difference in distribution was statistically highly significant in both cases $(\mathrm{F}=466.7 * *$, $740.3^{* *}, \mathrm{p}<0.01$, respectively). After 25 days, the total amount (100 g) of maize kernels was consumed in all replicates and both male and female weevils migrated mainly to barley (average $81 \%$ of individuals) and in smaller precent to wheat (19\% of individuals). The difference was highly significant $\left(\mathrm{t}=387.8^{* *}, \mathrm{p}<0.01\right)$.

Maize-reared weevils were predominantly found on maize, followed by barley, while wheat kernels did not attract adults. Weevils already chose maize kernels in the first assessment, after $12 \mathrm{~h}$ (Fig. 1), and the number of both males and females on maize remained high during the entire observation period. However, slightly higher preference of males than females for maize kernels was recorded. After $12 \mathrm{~h}$, the distribution of females was $93 \%$ on maize and $7 \%$ on barley, while males were distributed $89 \%$ on maize, $10 \%$ barley and $1 \%$ on wheat. The difference was highly significant $(\mathrm{t}=582.1$ **; $\mathrm{F}=962.5^{* *}, \mathrm{p}<0.01$, respectively). This trend was more evident when pairs (the presence of male and female weevils simultaneously) were considered. Such distribution of individuals remained the same until the observation on the day 25 . After 25 days, the entire amount of maize kernels was consumed and the weevils migrated mainly on barley ( $95 \%$ of weevils), and only $5 \%$ on wheat (in total, regardless on the sex). The difference was highly significant $\left(\mathrm{t}=744.1^{* *}, \mathrm{p}<0.01\right)$.

In the "Choice" test, after 50 days, in Petry dishes containing maize-reared weevils, the grain damage in maize (98.8\%) was statistically higher compared to both barley $(34.3 \%)$ and wheat $(6.7 \%)$. The damages significantly differed from wheat-reared population $\left(\mathrm{F}=1481.0^{* *}, \mathrm{p}<0.01\right.$, Eta Squared 1.00) and the amount of consumed grains after 50 days is presented in Table 1, as well as the results on the remained grain weight and weight loss $(\%)$. The highest grain loss in wheat-reared case was evident in maize $(84.3 \%)$, followed by barley $(43.6 \%)$, while the lowest loss occurred in wheat $(23.5 \%)$. The difference is statistically highly significant $\left(\mathrm{F}=167.4^{* *}, \mathrm{p}<0.01\right.$, Eta Squared 1.00).

\section{Ovipositional preference and progeny production}

Ovipositional preference was determined based on the progeny production. Significantly higher emergence of males and females from maize and barley grains, compared to the wheat, was recorded from maize-reared population (Table 1). On average, 18.62 males and 19.33 females emerged from maize, 12.71 males and 11.85 females emerged from barley, whereas 1.5 males and 2.0 females emerged from wheat. The differences between the number of emerged weevils from different substrates were significantly higher in maize-reared population, both for males $\left(\mathrm{F}=141.0^{* *}\right.$, Eta squared 1.00, $\mathrm{p}<0.01)$ and females $\left(\mathrm{F}=530.0^{* *}\right.$, Eta squared $\left.0.2, \mathrm{p}<0.01\right)$ as well as in a total number of emerged weevils $\left(\mathrm{F}=1377.6^{* *}\right.$, Eta squared $\left.1.00, \mathrm{p}<0.01\right)$. However, the difference in sex emergence was not significant on certain grains. 


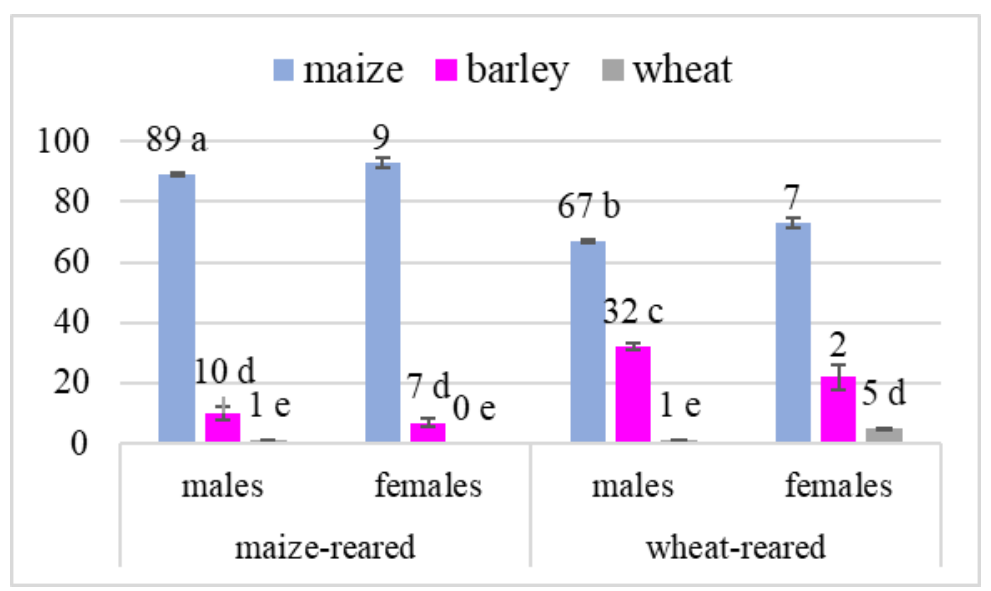

Figure 1. Distribution of Sitophilus oryzae males and females after $12 \mathrm{~h}$ on different cereal grains

From wheat-reared population, 9.8 males and 10.7 females emerged on maize, 7.6 males and 8.2 females on barley, while no progeny production was recorded on wheat (Table 1). The differences between sexes were not statistically significant, nor were the differences between maize and barley. However, the total differences, including wheat emerged progeny, were statistically highly significant for all, males $\left(\mathrm{F}=1544.7^{* *}\right.$, Eta squared 0.94, $\mathrm{p}<0.01)$, females $\left(\mathrm{F}=5644.0^{* *}\right.$, Eta squared $\left.0.63, \mathrm{p}<0.01\right)$ and total progeny $\left(\mathrm{F}=3214.8^{* *}\right.$, Eta squared $\left.1.00, \mathrm{p}<0.01\right)$.

Table 1. Host and feeding preferences of maize- and wheat-reared S. oryzae adults on different grains after 50 days

\begin{tabular}{|c|c|c|c|c|c|c|c|c|}
\hline & Treatment & $\begin{array}{c}\text { Grain } \\
\text { damage }(\%)\end{array}$ & RGW (g) & CGW (g) & $\begin{array}{c}\text { Weight loss } \\
(\%)\end{array}$ & $\begin{array}{c}\text { F1 progeny } \\
\text { males }^{\#}\end{array}$ & $\begin{array}{l}\text { F1 progeny } \\
\text { females }^{\#}\end{array}$ & F1 total \\
\hline \multirow{5}{*}{ Maize-reared } & Maize & $98.8 \pm 0.1 \mathrm{a}$ & $1.3 \pm 0.7 \mathrm{c}$ & $98.7 \pm 8.2 \mathrm{a}$ & $98.7 \pm 5.8 \mathrm{a}$ & $18.6 \pm 3.1 \mathrm{a}$ & $19.3 \pm 3.1 \mathrm{a}$ & $37.9 \pm 1.1 \mathrm{a}$ \\
\hline & Wheat & $6.7 \pm 0.2 c$ & $90.4 \pm 4.1 \mathrm{a}$ & $9.6 \pm 2.1 \mathrm{c}$ & $9.6 \pm 1.1 \mathrm{c}$ & $12.7 \pm 2.5 \mathrm{a}$ & $11.8 \pm 2.6 b$ & $24.5 \pm 0.9 \mathrm{~b}$ \\
\hline & Barley & $34.3 \pm 1.5 b$ & $66.4 \pm 3.6 b$ & $33.6 \pm 4.6 \mathrm{~b}$ & $33.6 \pm 6.2 b$ & $1.5 \pm 3.6 b$ & $2.0 \pm 0.2 \mathrm{c}$ & $5.2 \pm 0.7 \mathrm{c}$ \\
\hline & F value & $1481.0^{* * *}$ & $4599.0 * *$ & $2141.00 * *$ & $2141.0^{* *} *$ & $141.0^{* *}$ & $530.0 * *$ & $1377.6^{* *}$ \\
\hline & Eta squared & 1.000 & 1.000 & 1.000 & 1.000 & 0.994 & 0.183 & 0.998 \\
\hline \multirow{5}{*}{ Wheat-reared } & Maize & $84.3 \pm 0.7 \mathrm{a}$ & $14.7 \pm 2.7 \mathrm{c}$ & $85.3 \pm 9.1 \mathrm{a}$ & $85.3 \pm 2.5 \mathrm{a}$ & $9.8 \pm 0.8 \mathrm{a}$ & $10.7 \pm 2.3 \mathrm{a}$ & $20.5 \pm 3.2 \mathrm{a}$ \\
\hline & Wheat & $23.5 \pm 1.3 \mathrm{c}$ & $64.4 \pm 3.4 \mathrm{a}$ & $35.4 \pm 3.3 \mathrm{c}$ & $35.4 \pm 5.5 c$ & $7.6 \pm 1.1 \mathrm{a}$ & $8.2 \pm 1.1 \mathrm{a}$ & $15.8 \pm 2.4 \mathrm{a}$ \\
\hline & Barley & $43.6 \pm 2.1 \mathrm{~b}$ & $24.6 \pm 1.1 \mathrm{~b}$ & $75.4 \pm 7.4 \mathrm{~b}$ & $75.4 \pm 8.1 b$ & $0.0 \pm 0.0 \mathrm{a}$ & $0.0 \pm 0.0 \mathrm{~b}$ & $0.0 \pm 0.0 \mathrm{~b}$ \\
\hline & F value & $167.4^{* *}$ & $276.0^{* *} *$ & $654.2 * *$ & $654.2 * *$ & $1544.7^{* *}$ & $5644.0^{* *}$ & $3214.8 * *$ \\
\hline & Eta squared & 1.000 & 1.000 & 1.000 & 1.000 & 0.940 & 0.630 & 0.990 \\
\hline
\end{tabular}

Value $\pm \mathrm{SD} ; \mathrm{F}$ value - Bonferroni test; Eta squared - testing effect size; Values with the same letter are on the same level of significance for the confidence interval 95\%; ** $\mathrm{P}<0.01$; * $\mathrm{P}<0.05$; NS $-\mathrm{P}>0.05$; RGW -remained grain weight; CGV consumed grain weight; ${ }^{\#}$ progeny is presented as the number of offspring specimens

\section{Discussion}

Cereal grains differ significantly in attractiveness to $S$. oryzae, but this effect depends on several factors (Baker, 1988). This study tended to determine the main factors influencing host, feeding and oviposition preference of $S$. oryzae, in relation to Natal habitat preference induction hypothesis (NHPI) and/or food attractiveness.

In phytophagous insects, the NHPI predicts that females prefer to lay their eggs on the same host species on which they developed as larvae. NHPI hypothesis is based on 
the fact that experience with a natal habitat, namely food they developed on, shapes the habitat preferences of adults. However, since scientists used different terms to describe this phenomenon (Immelmann, 1975; Jaenike, 1983; Barron, 2001) it is unclear how frequently NHPI occurs and what are the implications of its occurrence. Results from several studies suggest that experience with plant chemical compounds (residuals) at the larval and/or pupal stage can influence adult preference to specific food. However, in most studies, the specific factors by which larval or pupal experience has changed adult behaviour were not identified because several learning mechanisms are involved.

Results on the host preference determined in this study indicate that wheat-reared $S$. oryzae adults preferred maize (43\% female and 39\% male individuals), to barley (35\% female and $32 \%$ male individuals) and wheat (22\% female and $29 \%$ male individuals). Maize-reared individuals, both males and females, had higher preference for maize ( $89 \%$ males and $93 \%$ females), less for barley (10\% males and $7 \%$ females), while wheat was of the least favourable choice (1\% of males). These findings are in accordance with Trematerra et al. (2013) who reported that inequality of maize, rice, barley and wheat in experiments indicate the fact that the preference is also influenced by genetic predispositions and that there are several factors that determine the behavioral response of $S$. oryzae to specific semiochemicals from food that are not related with natal exposure. On the other hand, this inequality could also be caused by the fact that maize, rice, barley and wheat kernels release different concentrations of odour. Also, as suggested by Trematerra et al. (2013), males visited more different food sources than females, which can be attributed to males pronounced mobility compared to females when food is available. Also, repeated "visits" by males could have occurred which is probably related to an increased probability in finding a suitable mating partner (Campbell, 2005; Guedes et al., 2010).

Price et al. (2011) reported that polyphagous herbivores use multiple host-plants for feeding and/or oviposition which is considered an evolutionary adaptation that enabled these species to adapt to variable environments. Unfortunately, the mechanisms of hostplant choice are not always easily defined and many factors are of importance, larval physiology, natural enemies, reproductive behaviour etc. (Bernays, 2001; Forister and Wilson, 2013; Bernays and Grahm, 2013). Female should choose the most suitable host plant for oviposition and for her offspring to develop. However, as reported by Nanthagopal and Uthamasamy (1989), female may make host choice decisions based on factors influencing her survival, such as nutritional quality of the plant.

For phytophagous insects such as $S$. oryzae, oviposition and food choice decisions are essentially the same (Singer et al., 1992). There is some evidence that oviposition preference and performance of offsprings can be correlated with heritable variability for oviposition preference as reported by Singer et al. (1988) for phytophagous insects in general, and by Fox (1993) for bruchids.

Based on the results of our study, previous feeding experience on feeding behaviour of $S$. oryzae virgin males and males was only confirmed in the case of maize-reared populations. Trematera et al. (2013) concluded that larval experience does not affect host preference in $S$. oryzae adults and also, it is not determinative in food selection. However, it should be mentioned that presented results correspond the specific grain used in the experiment (i.e. varieties) and no generalization should be made, since the data obtained may not be transferable to other commodities. The higher preference of maize and barley compared to wheat might be also due to a release of different concentrations of volatile compounds from maize, rice, barley and wheat kernels. Plant- 
borne volatiles play a role in food and host location, routing insect orientation and searching behaviour (Dicke and Baldwin, 2010). Germinara et al. (2008) indicate that for example, granary weevil adults can respond with different behavior to a wide range of cereal volatiles and that response may change depending on the concentration. Host finding behavior of weevils will depend on the balance of positive and negative volatile stimuli from grain as the relative concentrations of volatiles may change during storage. According to Visser (1986), phytophagous insects use volatiles from plant materials to locate suitable substrates and, as stated by Kanaujia and Levinson (1981) the presence of phagostimulatory compounds are considered crucial in the infestation process in storage pests. Additionally, Levinson and Kanaujia (1982) report that $S$. granarius male and female respond to various extracts from stored winter wheat. We can speculate that, since NHPI theory was not proven in our study, the food attractiveness, as a result of nutritive value and the presence of certain volatiles, was the factor influencing host, food and oviposition preference of $S$. oryzae to maize, primarily.

In our study, the feeding preference of $S$. oryzae towards wheat, maize, and barley was tested under "choice" conditions. Grain damage, grain weight loss and progeny production differed significantly among the various selected host grains. Grain weight loss was found to be the greatest in maize $(98.8 \%)$ and the lowest in wheat $(6.7 \%)$, for the population reared on maize. Subedi et al. (2009) also confirmed that, wheat was the least attractive host for $S$. oryzae compared to other cereals (rice, barley and maize). These authors reported that the greatest grain damage was observed in polished rice $(18.75 \%)$ and less in wheat $(16.25 \%)$ in a free-choice test. However, these findings are opposite to the results presented by Ansari (2003) where damages in wheat were the highest $(67.78 \%)$, while in maize were significantly lower $(40.97 \%)$. Subedi et al. (2009) reported that wheat was the most preferred host under no-choice conditions, however, when insects were offered a choice of polished rice and wheat, polished rice was the most preferred choice in "choice test". S. oryzae thus preferred polished rice under free-choice and wheat under no-choice.

Ovipostion and progeny production were higher on maize, regardless on the rearing history. In this study, the progeny production in maize-reared weevils was the highest on maize (37.9 in total), followed by barley ( 24.5 individuals; males + females) while the lowest on wheat (3.5 individuals). On wheat-reared population, the situation was similar, so in total (males + females) 20.5 weevils emerged from maize, 15.8 from wheat and none from barley. Our results also suggest that larger kernels, like maize are more desirable hosts for $S$. oryzae, comparing to small-kernel hosts, such as barley and wheat. Stejskal and Kucerova (1996) and Akhter et al. (2017) have demonstrated that $S$. oryzae prefers large kernels for oviposition than smaller, because they can contain more than one egg, comparing to smaller ones. Akhter et al. (2017) showed that S. oryzae adults preferred to lay larger number of eggs on pulse, which are considerably larger in size than other tested grains, rice and wheat. Russell (1968) also observed that weevil preferred to lay eggs in grains of larger size. Some other factors besides grains size also affect host and ovipositional preference. For example, seed with smooth surface are more preferred than rough and spiny ones (Salunkhe and Jadhav, 1982). Also, hardness of grain is very important factor which affects the oviposition rates (Teotia and Singh, 1968). Females accepted large kernels more quickly than small kernels and this contributed to increased oviposition in large kernels. The increase in the number of eggs per kernel appears to result from an increase in number of visits resulting in oviposition rather than an increase in the number of eggs laid during a visit (Campbell, 2002.) 


\section{Conclusion}

This study tended to determine the main factors influencing host, feeding and oviposition preference of $S$. oryzae, in relation to NHPI and/or food attractiveness.

The results of this study reveal that host, feeding and ovipositional preference of rice weevil, Sitophilus oryzae was not depending on the previous feeding experience. Host preference, based on the distribution of females and males on different grains, grain damage, grain weight loss and progeny production differed significantly among selected host grains. Maize was the most preferential grain, in all aspects, regardless on the rearing substrate, for both male and female weevils. Grain damage, weight loss and progeny production were higher on maize, regardless of the rearing history, followed by barley. Oviposition and progeny production were the highest on maize, regardless of the rearing history. Since NHPI theory was not proven in our study, we can speculate that food attractiveness was most probably result of nutritive value and the presence of certain volatiles, and therefore was the main factor influencing host, food and oviposition preference of $S$. oryzae to maize. Additionally, we can speculate that kernel size plays very important role in host preference since in both wheat- and maize-reared population, adult weevils chose larger maize kernels before smaller wheat and barley kernels as the most preferable food source.

Future research should be directed towards identification of different volatiles in host-plants which influence the behavior of $S$. oryzae and conduct behavioral studies with identified volatiles. Also, population parameters of $S$. oryzae should be conducted on different hosts in a large number of generations in order to evaluate the adaptive response of $S$. oryzae to the change of host.

\section{REFERENCES}

[1] Akhter, M., Sultana, S., Akter, T., Begum, S. (2017): Oviposition preference and development of rice weevil, Sitophilus oryzae (Lin.) (Coleoptera: Curculionidae) in different stored grains. - Bangladesh J. Zool. 45(2): 131-138.

[2] Ansari, A. R. (2003): Host preference, varietal screening and management of the rice weevil, S. oryzae (Coleoptera: Curculionidae). - M.Sc. Thesis (unpublished). Faculty of Agriculture, Maharana Pratap University of Agriculture and Technology, Udaipur, India.

[3] Atwal, A. S., Dhaliwal, G. S. (2002): Agriculture Pests of South Asia and Their Management. - Kalyani Publishers, Ludhiana.

[4] Baker, J. E. (1988): Development of four strains of Sitophilus oryzae (L.) (Coleoptera: Curculionidae) on barley, corn (maize), rice, and wheat. - J. Stored Prod. Res. 24(4): 193-198.

[5] Banerjee, T. C., Nazimuddin, S. (1985): Weight loss of wheat and rice caused by feeding of larvae and adults of the Sitophilus oryzae Linn. and Rhiozopertha dominica - F. Indian Journal of Agricultural Science 55(11): 703-706.

[6] Barron, A. B. (2001): The life and death of Hopkins' host-selection principle. - J. Insect Behav. 14: 725-737.

[7] Batta, Y. A. (2004): Control of rice weevil (Sitophilus oryzae L.) (Coleoptera: Curculionidae) with various formulations of Metarhizium anisopliae. - Crop Prot. 23: 103-108.

[8] Bernays, E. A. (2001): Neural limitations in phytophagous insects: implications for diet breadth and evolution of host affiliation. - Annu Rev Entomol 46: 703-727.

[9] Bernays, E., Grahm, M. (2013): On the evolution of host specificity in phytophagous arthropods. - Ecology 69: 886-892. 
[10] Blackiston, D. J., Casey, E. S., Weiss, M. R. (2008): Retention of memory through metamorphosis: Can a moth remember what it learned as a caterpillar? - PLoS One 3: 17.

[11] Boiça, Júnior, A. L., Souza, B. H. S., Costa, E. N. et al. (2017): Influence of fall armyworm previous experience with soybean genotypes on larval feeding behavior. Arthropod-Plant Interactions 11: 89-97. https://doi.org/10.1007/s11829-016-9469-1.

[12] Campbell, J. F. (2002): Influence of seed size on exploitation by the rice weevil, Sitophilus oryzae. - Journal of Insect Behavior 15: 429-445. https://doi.org/10.1023/A:1016225427886.

[13] Campbell, J. F. (2005): Fitness consequences of multiple mating on female Sitophilus oryzae L. (Coleoptera: Curculionidae). - Environ Entomol 34: 833-843.

[14] Cohen, J. (1992): A Power Primer. - Psychological Bulletin 112: 155-159.

[15] Corbet, S. A. (1985): Insect chemosensory responses: a chemical legacy hypothesis. Ecol Entomol 10: 143-153.

[16] Danho, M., Haubruge, E. (2003): Optimal Clutch Size and Oviposition Strategy for the Maize Weevil, Sitophilus Zeamais. - In: Credland, P. F., Armitage, D. M., Bell, C. H., Cogan, P. M., Highley, E. (eds.) Advances in Stored Product Protection. CAB International, Wallingford, pp. 59-64.

[17] Davies, J. (2004): The effect of natal experience on habitat preferences. - SIAS Faculty Publications. Paper 563. http://digitalcommons.tacoma.uw.edu/ias_pub/563.

[18] Davis, J. M., Stamps, J. A. (2004): The effect of natal experience on habitat preferences. - Trends Ecol Evol 19: 411-416.

[19] Dethier, V. G. (1954): Evolution of feeding preferences in phytophagous insects. Evolution 8: 33-54.

[20] Dethier, V. G. (1982): Mechanism of host-plant recognition. - Entomol. Exp. Appl. 31: 49-56.

[21] Dicke, M., Baldwin, I. T. (2010): The evolutionary context for herbivore-induced plant volatiles: beyond the 'cry for help'. - Trends Plant Sci. 15: 167-175.

[22] Forister, M. L., Wilson, J. S. (2013): The population ecology of novel plant-herbivore interactions. - Oikos 122: 657-666. http://doi.wiley.com/10.1111/j.16000706.2013.00251.x.

[23] Fox, C. W. (1993): A quantitative genetic analysis of oviposition preference and larval performance on two hosts in the bruchid beetle, Callosobruchus maculatus. - Evolution 47: 166-175.

[24] Germinara, G., De Cristofaro, A., Rotundo, G. (2008): Behavioral responses of adult Sitophilus granarius to individual cereal volatiles. - Journal of Chemical Ecology 34: 523-529.

[25] Guedes, N. M. P., Guedes, R. N. C., Campbell, J. F., Throne, J. E. (2010): Contest behaviour of maize weevil larvae when competing within seeds. - Anim Behav 79: 281289.

[26] Hopkins, A. D. (1917): A discussion of C. G. Hewitt's paper on "Insect Behaviour". - J Econ Entomol 10: 92-93.

[27] Immelmann, K. (1975): Ecological significance of imprinting and early learning. - Annu. Rev. Ecol. Syst. 6: 15-37.

[28] Jaenike, J. (1983): Induction of host preference in Drosophila melanogaster. - Oecologia 58: 320-325.

[29] Joshi, S. L., Karmacharya, B. B., Khadge. B. R. (1991): Trainer's Manual of Plant Protection. - Department of Agriculture, Central Agriculture Training Centre, Kathmandu, Nepal.

[30] Kanaujia, K. R., Levinson, H. Z. (1981): Phagostimulatory responses and oviposition behaviour of Sitophilus granarius L. to newly harvested and stored wheat grains. $-\mathrm{Z}$. Angew. Entomol. 91: 417-424. 
[31] Levinson, H. Z., Anaujia, K. R. (1982): Feeding and oviposition behaviour of the granary weevil (Sitophilus granarius L.) induced by stored wheat, wheat extracts and dummies. Z. Angew. Entomol. 93: 292-305.

[32] Nanthagopal, R., Uthamasamy, S. (1989): Life tables for spotted bollworm, Earias vitella (Fabricius), on four species of cotton. - Crop Prot 8: 133-136.

[33] Price, P. W., Denno, R. F., Eubanks, M. D., Finke, D. L., Kaplan, I. (2011): Insect Ecology. - Cambridge University Press, Cambridge.

[34] Russell, M. P. (1968): Influence of rice variety on oviposition and development of the rice weevil, S. oryzae, and the maize weevil, S. zeamais. - Ann. Entomol. Soc. Amer. 61(5): 1335-1336.

[35] Salunkhe, R., Jadhav, S. (1982): Weight loss of stored wheat caused by insect feeding. J. Econ. Entomol. 46: 609-610.

[36] Schoonhoven, L. M., Jerny, T., Van Loon, J. J. A. (1998): Insect-Plant Biology: From Physiology to Evolution. - Chapman and Hall, London.

[37] Singer, M. C., Ng, D., Thomas, C. D. (1988): Heritability of oviposition preference and its relationship to offspring performance within a single insect population. - Evolution 42: 977-985.

[38] Singer, M. C., Vasco, D., Parmesan, C., Thomas, C. D., Ng, D. (1992): Distinguishing between 'preference' and 'motivation' in food choice: an example from insect oviposition. - Animal Behaviour 44: 463-471.

[39] Singh, V. S., Bhatia, S. K., Murthy, B. N. (1980): Effect of hull on the resistance of barley varieties to the rice weevil Sitophilus oryzae L. infestation. - Indian Journal of Entomology 42(4): 576-581.

[40] Stejskal, V., Kucerova, Z. (1996): The effect of grain size on the biology of Sitophilus granarius (L.) (Coleoptera: Curculionidae). I. Oviposition, distribution of eggs and adult emergence. - J. Appl. Entomol. 120: 143-146.

[41] Subedi, S., Gc, Y. D., Thapa, R., Rijal, J. (2009): Rice weevil (Sitophilus oryzae L.) host preference of selected stored grains in Chitwan Nepal. - J. Inst. Agric. Anim. Sci. 30: 151-158.

[42] Teotia, T. P. S., Singh, V. S. (1968): On the oviposition behaviour and development of Sitophilus oryzae (L.) in various natural foods. - Indian J. Entomol. 30: 119-124.

[43] Thorpe, W. H., Jones, F. G. W. (1937): Olfactory conditioning in a parasitic insect and its relation to the problem of host selection. - Proc Roy Soc Lond B 124: 56-81.

[44] Trematerra, P., Lupi, C., Athanassiou, C. (2013): Does natal habitat preference modulate cereal kernel preferences in the rice weevil? - Arthropod-Plant Interactions 7. 10.1007/s11829-012-9243-y.

[45] Van Hemden, H. F., Sponagl, B., Wagner, E., Baker, T., Ganguly, S., Douloumpaka, S. (1996): Hopkins' 'host selection principle', another nail in its coffin. - Physiol Entomol 21: 325-328.

[46] Zakladnoľ, G. A., Ratanova, V. F. (Vera Flegontovna) (1987). Stored-Grain Pests and Their Control. - Balkema, Rotterdam. 